\title{
Striae gravidarum as a predictor of spontaneous preterm delivery: A case control study ${ }^{*}$
}

\author{
Sefa Kelekci ${ }^{1,2 \#}$, Servet Gencdal ${ }^{3}$, Orcun Ozdemir ${ }^{3}$, Emre Destegul ${ }^{3}$, Kiymet Handan Kelekci ${ }^{4,5}$ \\ ${ }^{1}$ Obstetrics and Gynecology Clinic, Aegean Education and Research Hospital, Ministry of Health, Izmir, Turkey \\ ${ }^{2}$ Department of Obstetrics and Gynecology, School of Medicine, Izmir Katip Celebi University, Izmir, Turkey \\ ${ }^{3}$ Obstetrics and Gynecology Clinic, Adana Numune Education and Research Hospital, Ministry of Health, Adana, Turkey \\ ${ }^{4}$ Dermatology Clinic, Ataturk Education and Research Hospital, Ministry of Health, Izmir, Turkey \\ ${ }^{5}$ Dermatology Clinic, Haseki Education and Research Hospital, Ministry of Health, Istanbul, Turkey \\ Email: " sefakelekci@gmail.com
}

Received 30 July 2012; revised 29 August 2012; accepted 8 September 2012

\begin{abstract}
Background/Aims: The association between striae gravidarum (SG) and preterm delivery may be postulated because of sharing similar poor organization of extracellular matrix in both skin and cervix. Our goal was to compare the frequency of striae gravidarum in women who gave preterm birth and women who gave term birth. Methods: A case-control study was conducted in women who gave preterm birth $(\mathrm{n}=$ 66) and age matched women who gave term birth $(\mathrm{n}=$ 68). Cases and controls were recruited from puerperal women consequently seen at delivery wards of perinatology unit. All women underwent dermatologic examination in terms of SG blindly to theirs gestational weeks of delivery. The frequency of SG was compared in all groups. Results: The frequency of SG was $63.6 \%$ in women with preterm birth and $54.4 \%$ in women with term birth $(p=0.278)$. SG is five times more common in late preterm group than in women with term group, but this difference was not statistically significant $[(p=0.227$, OR: $5.02, C I$ $95 \%(0.5-44.0)]$. The rate of preventive cream usage was not statistically different in women with SG and without SG ( $p=0.245)$. Conclusions: It seems that there was no statistically significant association between the risk of preterm labor and the presence of striae gravidarum. Larger prospective observational studies are needed to state expressly the probable clinical association between the presence of SG and preterm delivery.
\end{abstract}

Keywords: Preterm Delivery; Predictive; Screening; Striae Distensae; Striae Gravidarum; Term Delivery

\footnotetext{
"Disclosure: There is no financial or commercial conflict of interest This paper was presented in Lutfu Tat Symposium 2011.

${ }^{\#}$ Corresponding author.
}

\section{INTRODUCTION}

Preterm birth is the leading cause of perinatal morbidity and mortality worldwide [1]. Although improvements in neonatal care have increased survival for preterm infants, prevention researches and knowledge to date have not managed to reduce the rate of premature births.

Preventing preterm delivery remains one of the great challenges in modern obstetrics. A precise mechanism cannot be established in most cases; therefore, factors associated with preterm birth, but not obviously in the causal pathway, have been sought to explain preterm labor. Immensely lists of risk factors for preterm delivery were defined in obstetrics literature [2]. Due to limited resources and a paucity of beneficial interventions in women with low risk, most aspects of prematurity prevention are targeted at women with known risk factors for preterm birth.

Striae distensae (SD) is a common disfiguring cutaneous condition characterized by smooth linear bands of apparently atrophic skin, which occur in areas of dermal damage caused by stretching $[3,4]$. The pathogenesis of striae is unknown, but is probably related to changes that occur in the components of the extracellular matrix, including in fibrillin, elastin and collagen [5]. Collagen, elastin and fibrillin fibers are significantly reduced in SD compared with normal skin [6]. Our previous study found a significant association between prematurity and striae in women who gave premature birth probably as a result of poor organization of the extracellular matrix in the skin and cervix [7].

Defining risk factors for prediction of preterm birth is a reasonable goal for identification at risk women and allows initiation of risk-specific treatment. Additional research that clearly defines the mechanisms of which risk factors are related to preterm birth is crucial. In this case control study, our objective was to evaluate whether the presence of SG has a predictive value for preterm 
delivery.

\section{MATERIALS AND METHODS}

This case control study was conducted in perinatology clinics of Aegean Education and Research Hospital between September, 2008 and April, 2010. The study was approved by the local Research Ethics Committee and all participants gave informed consent before inclusion in the study.

Inclusion criteria were singleton delivery, primigravida, being non-smoker, not having previous striae before pregnancy, spontaneous preterm or term delivery, no history of prolonged steroid usage, not having systemic disease, Cushing's syndrome and cachetic states, not having infection, not having had preterm premature rupture of membrane/premature rupture of membrane and not having had invasive diagnostic procedure for fetal karyotyping. Exclusion criteria were induced preterm delivery, macrosomic fetus and postdate pregnancy.

Total 586 puerperal women were interviewed and 452 women were excluded according to selection criteria. Totally 134 puerperal women was eligible for this study. Cases were comprised of 66 women who gave preterm birth. Controls were comprised of 68 age matched women with term delivery consequently seen at delivery wards of perinatology clinics. Of 66 women with preterm deliveries, 59 women had early preterm deliveries and seven women had late preterm deliveries.

Eligible all puerperal women underwent a detailed dermatological examination for SG on the outer aspects of the thighs, buttocks, abdomen and breasts conducted by the second author (KHK), who was unaware whether the women gave term or preterm birth. Striae were graded based on the total surface area of the affected body part covered by SG: coverage of $<25 \%$ of the body part was considered to represent mild striae; coverage of $25 \%$ - 50\% was considered to represent moderate striae, and coverage of $>50 \%$ was considered to represent severe striae. All puerperal women were classified into one of two groups according to their history of preterm birth or term birth. Cases consisted of 66 women with preterm birth. Subgroup analysis was performed in early preterm birth (30 - 34 weeks' pregnancy) and in late preterm birth (35 - 37 weeks of pregnancy). After 37 weeks' pregnancy, it was denominated term delivery. The main outcome measure was the frequency of SG among all groups.

Demographic characteristics, presence or absence of SG, grade of SG, fetal gender, total weight gain during gestation and preventive cream usage were recorded and compared among all groups.

All statistical analysis was performed by SPSS version 19 (IBM statistics, NY, USA). Continuous variables were compared by student's t test for two independent groups. Chi square and fisher's exact tests were used to compare for categorical variables between groups. Significance level was accepted as 0.05 .

\section{RESULTS}

Total 134 puerperal women were included in this study. Demographic data were presented in Table 1. As expected gestational age, weight, BMI, weight gain during gestation and fetal weight were statistically significant in women with term delivery than in women with preterm delivery.

The overall frequency of SG in puerperal women of perinatology clinics was 59\% (79/134). The distribution of SG in all three groups was presented in Table 2. Striae were determined at a rate of $63.6 \%$ and $54.4 \%$ in women who gave premature birth and in women who gave term birth, respectively. The difference between cases and controls in terms of the presence of SD was not statistically significant [ $(p=0.278$, OR: $1.46(0.7-2.9)]$. SG is five times more common in late preterm groups than that in women with term delivery but this difference was also not statistically significant $[(p=0.227$, OR: 5.02, CI 95\% (0.5 - 44.0)].

In addition there is no statistically significant difference in terms of grade of SG and fetal gender between cases and controls (Table 3 ). The rates of preventive cream usage were $66.7 \%$ and $60.3 \%$ in women with preterm birth and in women with term birth, respectively. The difference was not statistically significant ( $\mathrm{p}=$ 0.444).

In comparison of characteristics of women with SG and without SG, when the puerperal women were divided into subgroups according to absence or presence of SG, maternal age, gestational age, BMI, weight gain, fetal weight and fetal gender were similar in both groups (Table 4). In view of the use of preventive cream use between women with SG and women without SG, there

Table 1. Characteristics of puerperal women analyzed.

\begin{tabular}{cccc}
\hline & $\begin{array}{c}\text { Preterm Delivery } \\
\left(\mathrm{n}_{1}=66\right)\end{array}$ & $\begin{array}{c}\text { Term Delivery } \\
\left(\mathrm{n}_{2}=68\right)\end{array}$ & $\begin{array}{c}\mathrm{p} \\
\text { Value }^{*}\end{array}$ \\
\hline $\begin{array}{c}\text { Age (years old) } \\
\text { Gestational Age } \\
\text { (weeks) }\end{array}$ & $26.2 \pm 5.1$ & $25.8 \pm 4.1$ & 0.666 \\
Weight (kg) & $62.4 \pm 1.7$ & $38.2 \pm 1.1$ & 0.001 \\
Height (cm) & $165.1 \pm 5.1$ & $164.2 \pm 4.8$ & 0.314 \\
BMI (kg/m $\left.{ }^{2}\right)$ & $24.9 \pm 3.1$ & $26.9 \pm 3.2$ & 0.001 \\
Weight Gain (kg) & $10.3 \pm 3.4$ & $12.7 \pm 2.7$ & 0.001 \\
Fetal Weight \\
(gram)
\end{tabular}

*Values are given as Mean \pm SD. 
Table 2. The distribution of striae gravidarum in all groups.

\begin{tabular}{cccc}
\hline Groups & $\begin{array}{c}\text { Absent SG } \\
\left(\mathrm{n}_{1}=55\right)\end{array}$ & $\begin{array}{c}\text { Present SG } \\
\left(\mathrm{n}_{2}=79\right)\end{array}$ & $\mathrm{p}$ Value \\
\hline $\begin{array}{c}\text { Term } \\
\text { Delivery }\end{array}$ & $31 / 68(45.6 \%)$ & $37 / 68(54.4 \%)$ & ${ }^{*} 0.453$ \\
$\begin{array}{c}\text { Early Preterm } \\
\text { Delivery }\end{array}$ & $23 / 59(39 \%)$ & $36 / 59(61 \%)$ & ${ }^{* *} 0.408$ \\
$\begin{array}{c}\text { Late Preterm } \\
\text { Delivery }\end{array}$ & $1 / 7(14.3 \%)$ & $6 / 7(85.7 \%)$ & ${ }^{* * * *} 0.227$ \\
Total & $55 / 134(41 \%)$ & $79 / 134(59 \%)$ & 0.28 \\
\hline
\end{tabular}

Term vs preterm, $\mathrm{p}=0.453 ;{ }^{* * *}$ Early vs late preterm, $\mathrm{p}=0.408 ;{ }^{* * * *}$ Term vs early preterm, $\mathrm{p}=0.227$.

Table 3. Main outcome measures of cases and controls.

\begin{tabular}{cccc}
\hline & $\begin{array}{c}\text { Preterm } \\
\text { Delivery } \\
\left(\mathrm{n}_{1}=66\right)\end{array}$ & $\begin{array}{c}\text { Term } \\
\text { Delivery } \\
\left(\mathrm{n}_{2}=68\right)\end{array}$ & p Value \\
\hline Striae Gravidarum & & & \\
Absent n (\%) & $24(36.4 \%)$ & $31(45.6 \%)$ & \\
Present n (\%) & $42(63.6 \%)$ & $37(54.4 \%)$ & 0.278 \\
$\begin{array}{c}\text { Mild SD n (\%) } \\
\text { Moderate SD } \\
\text { n (\%) }\end{array}$ & $38(90.5 \%)$ & $35(94.6 \%)$ & \\
\hline Fetal Gender & $4.5 \%)$ & $2(5.4 \%)$ & 0.679 \\
Female n (\%) & $32(48.5 \%)$ & $35(51.5 \%)$ & \\
Male n (\%) & $34(51.5 \%)$ & $33(48.5 \%)$ & 0.730 \\
\hline Cream Usage & & & \\
Absent n (\%) & $22(33.3 \%)$ & $27(39.7 \%)$ & \\
Present n (\%) & $44(66.7 \%)$ & $41(60.3 \%)$ & 0.444 \\
\hline
\end{tabular}

is no statistically significant difference between groups $(\mathrm{p}=0.156)$.

\section{DISCUSSION}

This case control study showed that the frequency of striae gravidarum in women with late preterm birth is five times more than the women without preterm birth in spite of tendency towards to significance. However SG has had no predictive value for preterm birth statistically.

The causes of SD remain unknown but the condition is clearly related to changes in the structures that provide the skin with its tensile strength and elasticity. Mechanical stretching of the skin in association with hormonal factors has been implicated in the pathogenesis of SD. Proposed risk factors for the development of SD include family history, race, skin type, age, weight gain and poor nutrition; however, most of these suggestions have not been substantiated $[8,9]$. Striae gravidarum usually begins to appear in the second half of pregnancy and occur as
Table 4. Characteristics of women with striae gravidarum and without striae gravidarum.

\begin{tabular}{cccc}
\hline & $\begin{array}{c}\text { Absent SG } \\
\left(\mathrm{n}_{1}=55\right)\end{array}$ & $\begin{array}{c}\text { Present SG } \\
\left(\mathrm{n}_{2}=79\right)\end{array}$ & p Value \\
\hline Age & $25.8 \pm 4.6$ & $26.1 \pm 4.6$ & 0.708 \\
Gest. Age & $35.4 \pm 3.2$ & $35.3 \pm 3.2$ & 0.885 \\
Weight & $69.4 \pm 9.1$ & $70.7 \pm 8.4$ & 0.412 \\
Height & $164.6 \pm 4.5$ & $164.6 \pm 5.2$ & 0.974 \\
BMI & $25.6 \pm 3.4$ & $26.1 \pm 3.1$ & 0.392 \\
Weight Gain & $11.2 \pm 2.7$ & $11.7 \pm 2.9$ & 0.279 \\
Fetal Weight & $2907.7 \pm 819.9$ & $2785.1 \pm 739.1$ & 0.368 \\
\hline Fetal Gender & & & \\
Female n (\%) & $29(43.3 \%)$ & $38(56.7 \%)$ & \\
Male n (\%) & $26(38.8 \%)$ & $41(61.2 \%)$ & 0.598 \\
\hline Cream Usage & & & \\
Absent n (\%) & $24(49 \%)$ & $25(51 \%)$ & \\
Present n (\%) & $31(36.5 \%)$ & $54(63.5 \%)$ & 0.156 \\
\hline
\end{tabular}

pigmented marks in all quadrants of the abdomen. In the largest study, $71 \%$ of puerperal women reported striae developing before 28 weeks of pregnancy and $29 \%$ after 28 weeks [10]. Therefore we choose 30 week's pregnancy in this study as a lower limit of pregnancy.

In our previous study [7], gravidity, parity, abortion, weight and height were found to be statistically significant factors for SD. This result was similar to the findings of Thomas et al. [11], who found an association with BMI where striae gravidarum was more common in the overweight women. Another study reported that women who developed SG had higher maternal BMI and higher gestational age at delivery and higher birth weight of baby [12]. The confounding factors such as low maternal age, high BMI, excessive maternal weight gain and large baby during pregnancy were consistent with the other studies $[10,13]$. In our study, due to selection criteria, gestational age, weight, BMI, weight gain during gestation and fetal weight were higher in controls. These confounding factors that are expected to decrease of the frequency of SG are more common in women with term birth than in women with preterm birth in this study, in case of being similar frequency of SG in both groups, this statistical insignificant difference despite presence of the negative confounding effect may interpret in favor of having a predictive value of SG for late preterm birth. The probable clinical association of SG with preterm delivery should be considered preliminary and awaits further prospective observational study.

The pathogenesis of striae is unknown, but is probably 
related to changes that occur in the components of the extracellular matrix, including in fibrillin, elastin and collagen [5]. Collagen, elastin and fibrillin fibers are significantly reduced in SD compared with normal skin [6]. A recent study found a correlation between the presence of striae and pelvic relaxation, a condition associated with decreased collagen content [14]. Because of similar pathogenesis in cervical changes of preterm labor, there might be a correlation between SD and early preterm delivery. Therefore defining risk factors for prediction of preterm birth is a reasonable goal for identification of at-risk women allows initiation of riskspecific treatment [15].

In present study, there were no significant differences in terms of preventive cream usage between absent SG group and present SG groups. It was unclear whether it was the ointment, the massage, or a specific component of the ointment that was effective in preventing striae gravidarum [16]. Many creams have been used to prevent SG, but most have been found to be ineffective $[10,17]$. In a recent study, it was found that the cocoa butter cream appeared to be no better than the placebo for preventing striae gravidarum [18].

In conclusion, preterm birth is the leading cause of perinatal morbidity and mortality currently. Defining risk factors for prediction of preterm birth is a reasonable goal for identification of women at risk. The frequency of striae in women with late preterm birth is five times more than that in women without preterm birth. The risk of preterm labor had not statistically significant increase with the occurrence of striae gravidarum. Due to limitations of case control studies this probable clinical association between SG and preterm delivery should be evaluated by further prospective observational study.

\section{REFERENCES}

[1] Lawn, J.E., Cousens, S. and Zupan, J. (2005) 4 million neonatal deaths. When? Where? Why? Lancet, 365, 891900. doi:10.1016/S0140-6736(05)71048-5

[2] Goldenberg, R.L., Culhane, J.F., Iams, J.D. and Romero, R. (2008) Epidemiology and causes of preterm birth. Lancet, 371, 75-84. doi:10.1016/S0140-6736(08)60074-4

[3] Viennet, C., Bride, J., Cohen-Letessier, A. and Humbert, P. (2001) Mechanical behavior of fibroblasts included in collagen lattices. Journal de la Société de Biologie, 195, 427-433.

[4] Burrows, N.P. and Lovell, C.R. (2004) Disorders of connective tissue. In: Burns, T., Breathnach, S., Cox, N., Griffith, C., Eds., Rook's Textbook of Dermatology, 7th Edition, Blackwell Science, Oxford, 46-47. doi:10.1002/9780470750520.ch46

[5] Watson, R.E., Parry, E.J. and Humphries, J.D. (1998)
Fibrillin microfibrils are reduced in skin exhibiting striae distensae. British Journal of Dermatology, 138, 931-937. doi:10.1046/j.1365-2133.1998.02257.x

[6] Lee, K.S., Rho, Y.J. and Jang, S.I. (1994) Decreased expression of collagen and fibronectin genes in striae distensae tissue. Clinical and Experimental Dermatology, 19, 285-288. doi:10.1111/j.1365-2230.1994.tb01196.X

[7] Kelekci, K.H., Kelekci, S., Destegul, E., Aksoy, A., Sut, N. and Yılmaz, B. (2011) Prematurity: Is it a risk factor for striae distensae? International Journal of Dermatology, 50, 1240-1245. doi:10.1111/j.1365-4632.2011.04899.x

[8] Schuster, S. (1979) The cause of striae distensae. Acta Dermato-Venereologica, 59, 161-169.

[9] Chang, A.L., Agredana, X.Z. and Kimball, A.B. (2004) Risk factors associated with striae gravidarum. Journal of the American Academy of Dermatology, 51, 881-885. doi:10.1016/j.jaad.2004.05.030

[10] Atwal, G.S., Manku, L.K., Griffiths, C.E. and Palson, D.W. (2006) Striae gravidarum in primiparae. British Journal of Dermatology, 155, 965-969. doi:10.1111/j.1365-2133.2006.07427.x

[11] Thomas, R.G. and Liston, W.A. (2004) Clinical associations of striae gravidarum. Journal of Obstetrics \& Gynaecology, 24, 270-271. doi:10.1080/014436104101001660779

[12] J.-Orh, R., Titapant, V., Chwennattana, P. and Tontisirin, P. (2008) Prevalence and associate factors for striae gravidarum. Journal of the Medical Association of Thailand, 91, 445-451.

[13] Osman, H., Rubeiz, N., Tamim, H. and Nassar, A.H. (2007) Risk factors for the development of striae gravidarum. American Journal of Obstetrics \& Gynecology, 196, 62.e1-62.e4

[14] Salter, S.A., Batra, R.S. and Rohrer, T.E. (2006) Striae and pelvic relaxation: Two disorders of connective tissue with strong association, Journal of Investigative Dermatology, 126, 1475-1478. doi:10.1038/sj.jid.5700258

[15] Smith, L.K., Draper, E.S., Manktelow, B.N., Dorling, J.S. and Field, D.J. (2007) Socioeconomic inequalities in very preterm birth rates. Archives of Disease in Childhood. Fetal and Neonatal Edition, 92, 11-14. doi:10.1136/adc.2005.090308

[16] Wierrani, F., Kozak, W., Schramm, W. and Grunberger, W. (1992) Attempt of preventive treatment of striae gravidarum using preventive massage ointment administration [in German]. Wiener Klinische Wochenschrift, 104, 4244.

[17] Madlon-Kay, D.J. (1993) Striae gravidarum. Folklore and fact. Archives of Family Medicine, 2, 507-511. doi:10.1001/archfami.2.5.507

[18] Buchanan, K., Fletcher, H.M. and Reid, M. (2010) Prevention of striae gravidarum with cocoa butter cream. International Journal of Gynecology \& Obstetrics, 108, 6568. 